\title{
Modelling dications in the diurnal ionosphere of Venus
}

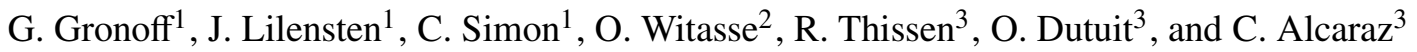 \\ ${ }^{1}$ Laboratoire de Planétologie de Grenoble, Université Joseph Fourier - CNRS, France \\ e-mail: guillaume.gronoff@obs.ujf-grenoble.fr \\ 2 Research and Scientific Support Department of ESA, ESTEC, Noordwijk, The Netherlands \\ 3 Laboratoire de Chimie Physique - CNRS - UMR 8000, Univ. Paris Sud, 91405 Orsay, France
}

Received 7 July 2006 / Accepted 9 December 2006

\section{ABSTRACT}

\begin{abstract}
Context. Previous studies have shown that doubly-charged positive ions, including molecular ions, can have detectable densities in the ionospheres of Mars, Titan, and the Earth.

Aims. In the present paper, we continue our approach by modelling the Venusian ionosphere. The neutral atmosphere of Venus has a similar composition to the ones encountered in the other terrestrial planets, with carbon dioxide (as on Mars), nitrogen (as on Earth and Titan), and atomic oxygen (as on Earth).

Methods. We computed the doubly-charged positive ion production through photoionisation (primary production) and electron impact ionisation (secondary production). We computed the densities under the photochemical equilibrium assumption.

Results. We predict a $\mathrm{CO}_{2}^{++}$layer centred around $140 \mathrm{~km}$ altitude with a density reaching 30 dications per $\mathrm{cm}^{3}$ in active solar conditions and $\mathrm{a} \mathrm{N}_{2}{ }^{++}$layer centred around a $140-150 \mathrm{~km}$ altitude with density reaching $0.3 \mathrm{~cm}^{-3}$. We find good agreement between the modelled $\mathrm{O}^{++}$densities and Pioneer Venus Orbiter measurements. Finally, we investigate the problem of possible detection of these ions by the European spacecraft Venus Express.

Conclusions. Although molecular doubly-charged positive ion densities are low, these ions cannot be considered as negligible compared to other minor ion species. Their detection should be possible in the future through remote sensing or in-situ methods including ion mass spectrometry and UV spectroscopy.
\end{abstract}

Key words. planets and satellites: individual: Venus - atmospheric effects - Sun: UV radiation - space vehicles: instruments

\section{Introduction}

The study of planetary ionospheres is among the major scientific goals of many planetary missions. Venus Express (VEX), a European Space Agency mission, is the first dedicated mission to Venus since Magellan in the 1990s.

The VEX spacecraft entered into the Venus orbit on 11 April 2006, and it has since then started acquiring its planetary data, thereby providing a global view of Venus' atmosphere. The scientific goals cover the following themes: atmosphere dynamics, structure, composition, clouds and haze, radiative balance, surface properties, and - most important in the frame of this paper - plasma/escape processes. The study of the ionosphere of Venus is clearly included in the last theme, and the following experiments are expected to contribute: VERA (Häusler et al. 2006), SPICAV (Bertaux et al. 2006), and ASPERA (Barabash et al. 2006). A review of our current knowledge of certain key topics associated with the aeronomy of Venus can be found in Witasse \& Nagy (2006). We report here on a study of the modelling of doubly-charged positive ions in the diurnal ionosphere.

Plasma densities depend on production and loss mechanisms, as well as on the dynamics. Production can be of either a chemical or physical origin. In the latter case we consider two sources: photoabsorption (called primary photoproduction) and electron impact ionisation (called secondary production). In optically thin upper atmospheres, as in the case for Venus in the EUV range $(<100 \mathrm{~nm})$ above $100 \mathrm{~km}$, the primary production is computed through a Beer-Lambert law. The secondary production computation requires solving a kinetic transport equation (Lilensten \& Blelly 2002). In Witasse et al. (2002, 2003), this approach was adapted to Mars, allowing the authors to predict the existence of a $\mathrm{CO}_{2}{ }^{++}$layer. The same approach was developed by Simon et al. (2005) and Lilensten et al. (2005) for the Earth and Titan cases, respectively. The present paper aims at presenting the calculation of the three main stable dications in the Venusian ionosphere: $\mathrm{O}^{++}, \mathrm{CO}_{2}{ }^{++}$, and $\mathrm{N}_{2}{ }^{++}$. The $\mathrm{O}^{++}$dication has already been detected and quantified in the Venusian ionosphere by Pioneer Venus Orbiter (PVO) (Taylor et al. 1980), eventually allowing comparisons to be made with models such as the one of Fox \& Victor (1981). The $\mathrm{CO}_{2}{ }^{++}$and $\mathrm{N}_{2}{ }^{++}$molecular ions have not yet been identified and are modelled here for the first time in the ionosphere of Venus.

\section{Modelling dication densities}

Several input parameters must be taken into account for modelling the contribution doubly-charged ions in terms of productions and densities: the solar flux and the neutral atmosphere.

We use the semi-empirical solar EUV/XUV model called solar 2000 (Tobiska 1991, 1993; Tobiska \& Eparvier 1998). Like most models currently used in planetary aeronomy (Torr \& Torr 1985, 1979; Richards et al. 1994), this model is based on measurements recorded onboard the Dynamics Explorer satellites (Hinteregger et al. 1973) and onboard rockets. It also takes data into account from other sources, such as the SME, OSO, and AEROS spacecrafts, as well as ground-based facilities. The UV spectrum is divided into 39 energy boxes. The neutral 
atmosphere is yielded by the VTS3 model (Hedin et al. 1983), restricted to the main species $\left(\mathrm{CO}_{2}, \mathrm{~N}_{2}, \mathrm{CO}, \mathrm{O}, \mathrm{He}\right)$. This model is run for the conditions that match the orbit in terms of solar activity, location, time, and solar-zenith angle. The $\mathrm{CO}_{2}$ molecule is the major constituent below $160 \mathrm{~km}$ altitude, $\mathrm{O}$ below $340 \mathrm{~km}$, while $\mathrm{H}$ and $\mathrm{He}$ become dominant above. The $\mathrm{H}$ density is about $10^{5} \mathrm{~cm}^{-3}$ above $150 \mathrm{~km}$ altitude and does not affect the results below $280 \mathrm{~km}$ (Fox \& Sung 2001). However, as will be shown later, the evolution of hydrogen density has an influence on the $\mathrm{O}^{++}$density above this altitude. In order to take its variations into account, we use the results of Hartle et al. (1996) who examined the solar cycle variations of the hydrogen in the thermosphere of Venus. The altitude range for our computations is $110-400 \mathrm{~km}$ altitude.

\subsection{Photochemistry}

The dication density computed for a neutral species $\mathrm{A}$ is given by

$N_{\mathrm{A}^{++}}=\frac{P_{\mathrm{A}^{++}}^{\text {Photo }}+P_{\mathrm{A}^{++}}^{\text {Impact }}}{N_{\mathrm{e}} \cdot k_{\mathrm{dr}}+\sum_{\mathrm{X}} N_{\mathrm{X}} \cdot k_{\mathrm{X}}+\frac{1}{\tau}}$

where $P_{\mathrm{A}^{++}}^{\text {Photo }}$ is the primary ion photoproduction and $P_{\mathrm{A}^{++}}^{\text {Impact }}$ the secondary production created through electron-neutral collisions. The values of $P_{\mathrm{A}^{++}}^{\text {Photo }}$ and $P_{\mathrm{A}^{++}}^{\text {Impact }}$ are direct outputs of the transport code (see below Lilensten \& Blelly 2002; Simon et al. 2005). In the case of $\mathrm{O}^{++}$, there are two different ionisation processes: direct double ionisation of the atomic oxygen and single ionisation of $\mathrm{O}^{+}$. Both are taken into account. We do not deal with the ionisation of $\mathrm{CO}_{2}^{+}$and $\mathrm{N}_{2}^{+}$because these very minor ions in the Venusian ionosphere (Fox \& Sung 2001) cannot yield a significant amount of dications. The constant $\tau$ represents the natural lifetime of the molecular doubly-charged ion, and $N_{\mathrm{X}}$ is the density of a neutral reactant $\mathrm{X}, k_{\mathrm{X}}$ the reaction rate in $\mathrm{cm}^{3} \mathrm{~s}^{-1}$, and $N_{\mathrm{e}}$ represents the electron density. In the following, $T_{\mathrm{e}}$ is the electronic temperature and $T_{\mathrm{n}}$ the neutral one. The processes for each species taken into account in the modelling are described below. A description of the techniques used for laboratory measurements can be found in Dutuit et al. (1996) and Franceschi et al. (2003).

\subsection{1. $\mathrm{CO}_{2}^{++}$}

- Dissociative recombination: $\mathrm{CO}_{2}^{++}+\mathrm{e}^{-}$: $k_{\mathrm{dr}}=(6.2 \pm 1.5) \times 10^{-7} \times \sqrt{\frac{300}{T_{\mathrm{e}}}} \mathrm{cm}^{3} \mathrm{~s}^{-1}$ (Seiersen et al. 2003a).

- Reaction with $\mathrm{CO}_{2}$ : $k_{\mathrm{CO}_{2}}=(2.1 \pm 0.4) \times 10^{-10} \times \sqrt{\frac{T_{\mathrm{n}}}{300}} \mathrm{~cm}^{3} \mathrm{~s}^{-1}$ (Franceschi et al. 2003).

- Dissociation: $\tau=4 \mathrm{~s}$ (Mathur et al. 1995; Mathur 2004).

- Reaction with O: the reaction rate has never been measured, due to the very unstable and reactive character of the oxygen radical. For this purpose, we have performed a series of $\mathrm{CO}_{2}{ }^{++}$reaction rate measurements of stable target species, in order to get a final estimate of the reaction rate constant. We obtain

$k_{\mathrm{O}}=(2 . \pm 1.2) \times 10^{-9} \mathrm{~cm}^{3} \mathrm{~s}^{-1}$ (this work).

\subsection{2. $\mathrm{N}_{2}^{++}$}

- Dissociative recombination: $\mathrm{N}_{2}{ }^{++}+\mathrm{e}^{-}$:

$k_{\mathrm{dr}}=(5.8 \pm 1.5) \times 10^{-7} \times \sqrt{\frac{300}{T_{\mathrm{e}}}} \mathrm{cm}^{3} \mathrm{~s}^{-1}$ (Seiersen et al. 2003b).

- Reaction with $\mathrm{CO}_{2}$ :

$k_{\mathrm{CO} 2}=(3 . \pm 1.8) \times 10^{-9} \mathrm{~cm}^{3} \mathrm{~s}^{-1}$ (laboratory measurements, this work).

- Reaction with O:

$k_{\mathrm{O}}=(1.8 \pm 1.) \times 10^{-9} \mathrm{~cm}^{3} \mathrm{~s}^{-1}$ (this is also an estimate, based on measurements with stable targets; this work).

- Reaction with $\mathrm{N}_{2}$ : $k_{\mathrm{N}_{2}}=(2.7 \pm 0.7) \times 10^{-9} \mathrm{~cm}^{3} \mathrm{~s}^{-1}$ (Lilensten et al. 2005).

- Dissociation: $\tau=3$ s (Mathur et al. 1995).

\subsection{3. $\mathrm{O}^{++}$}

- Recombination with electrons: $\mathrm{O}^{++}+\mathrm{e}^{-}$: $k_{\mathrm{r}}=2.1 \times 10^{-11} \times \frac{4}{\sqrt{T_{\mathrm{av}}}} \mathrm{cm}^{3} \mathrm{~s}^{-1}$ where $T_{\mathrm{av}}=\frac{T_{\mathrm{e}}+T_{\mathrm{i}}}{2}$ (Nakada \& Singer 1968). Surprisingly, this coefficient for $\mathrm{O}^{++}$depends here on an averaged electron-ion temperature, whereas the preceding dissociative recombination coefficients (for $\mathrm{N}_{2}{ }^{++}$and $\mathrm{CO}_{2}{ }^{++}$) only depend on the electron temperature. Introducing an average temperature for the dissociative recombination of $\mathrm{CO}_{2}{ }^{++}$and $\mathrm{N}_{2}{ }^{++}$makes a difference of $16 \%$ at $400 \mathrm{~km}$ and $20 \%$ at $150 \mathrm{~km}$ on the dissociative recombination alone. This difference becomes negligible for the total densities when considering all the reactions.

- Reaction with $\mathrm{CO}_{2}$ : $k_{\mathrm{CO}_{2}}=2 . \times 10^{-9} \mathrm{~cm}^{3} \mathrm{~s}^{-1}$ (Fox \& Victor 1981).

- Reaction with $\mathrm{N}_{2}$ :

$k_{\mathrm{N}_{2}}=(1.3 \pm 0.3) \times 10^{-9} \mathrm{~cm}^{3} \mathrm{~s}^{-1}$ (we assumed that the neutral temperature is $300 \mathrm{~K}$ at the considered altitude) (Johnsen \& Biondi 1978).

- Reaction with O: $k_{\mathrm{O}}=(1.06 \pm 0.40) \times 10^{-10} \mathrm{~cm}^{3} \mathrm{~s}^{-1}$ (Simon et al. 2005) (based on model).

- Reaction with CO: $k_{\mathrm{CO}}=1.6 \times 10^{-9} \mathrm{~cm}^{3} \mathrm{~s}^{-1}$ (Fox \& Victor 1981).

- Reaction with $\mathrm{H}$ : $k_{\mathrm{H}}=1.1 \times 10^{-9} \mathrm{~cm}^{3} \mathrm{~s}^{-1}$ (Honvault et al. 1995).

- Reaction with He: $k_{\mathrm{He}}=1.1 \times 10^{-10} \mathrm{~cm}^{3} \mathrm{~s}^{-1}\left(\right.$ at $T_{\mathrm{n}}=1000$, predominant above $300 \mathrm{~km}$ altitude) (Kimura et al. 1996).

\subsection{Ionisation and double-ionisation thresholds}

We consider 32 ionisation processes, summarised in Table 1 . The cross sections for the single ionisation of neutral species are explained in Witasse et al. (2002, 2003), Lilensten et al. (2005), Simon et al. (2005), and references therein. In Table 2, we give the references for the double-ionisation cross sections of the different neutral species. The $\mathrm{N}_{2}$ double-photoionisation cross section and its evolution with photon energy was estimated on the basis of a method proposed in Samson (1990). Samson shows that the double-photoionisation cross section $\sigma_{\mathrm{h} v}^{++}$of a species A $\left(\mathrm{A}+\mathrm{h} v \rightarrow \mathrm{A}^{++}+2 \mathrm{e}^{-}\right)$is proportional to the electron-impact ionisation $\sigma_{\mathrm{e}}^{+\rightarrow++}$ of the monocation $\left(\mathrm{A}^{+}+\mathrm{e}^{-} \rightarrow \mathrm{A}^{++}+2 \mathrm{e}^{-}\right)$, multiplied by the total photoabsorption $\sigma_{\mathrm{h} v}^{\mathrm{abs}}$ of the neutral species $(\mathrm{A}+\mathrm{h} v \rightarrow$ ?). The proportionality constant $q$ is estimated as $0.133 \times 10^{16} \mathrm{~cm}^{-2}$ in the case of $\mathrm{N}_{2}^{++}$. Thus, we have: $\sigma_{\mathrm{h} v}^{++}=$ $q \sigma_{\mathrm{e}}^{+\rightarrow++} \sigma_{\mathrm{h} v}^{\mathrm{abs}}$. 
Table 1. Summary of the ion productions taken into account here and their corresponding ionisation thresholds.

\begin{tabular}{llc}
\hline \hline $\begin{array}{l}\text { Ionisation } \\
\text { processes }\end{array}$ & Processes & $\begin{array}{c}\text { Threshold } \\
(\mathrm{eV})\end{array}$ \\
\hline 1 & $\mathrm{CO}_{2} \rightarrow \mathrm{CO}_{2}^{+}(\mathrm{X})+\mathrm{e}^{-}$ & 13.77 \\
2 & $\mathrm{CO}_{2} \rightarrow \mathrm{CO}_{2}{ }^{+}(\mathrm{A}+\mathrm{B})+\mathrm{e}^{-}$ & 17.310 \\
3 & $\mathrm{CO}_{2} \rightarrow \mathrm{CO}_{2}{ }^{+}(\mathrm{C})+\mathrm{e}^{-}$ & 19.39 \\
4 & $\mathrm{CO}_{2} \rightarrow \mathrm{CO}^{+}+\mathrm{O}+\mathrm{e}^{-}$ & 19.446 \\
5 & $\mathrm{CO}_{2} \rightarrow \mathrm{O}^{+}+\mathrm{CO}+\mathrm{e}^{-}$ & 19.07 \\
6 & $\mathrm{CO}_{2} \rightarrow \mathrm{C}^{+}+\mathrm{O}_{2}+\mathrm{e}^{-}$ & 27.9 \\
7 & $\mathrm{CO}_{2} \rightarrow \mathrm{CO}_{2}^{++}+2 \mathrm{e}^{-}$ & 37.6 \\
8 & $\mathrm{~N}_{2} \rightarrow \mathrm{N}_{2}^{+}+\mathrm{e}^{-}$ & 15.6 \\
9 & $\mathrm{~N}_{2} \rightarrow \mathrm{N}^{+}+\mathrm{N}^{-}$ & 24.3 \\
10 & $\mathrm{~N}_{2} \rightarrow \mathrm{N}_{2}^{++}+2 \mathrm{e}^{-}$ & 43.6 \\
11 & $\mathrm{CO} \rightarrow \mathrm{CO}^{+}+\mathrm{e}^{-}$ & 14.01 \\
12 & $\mathrm{CO} \rightarrow \mathrm{C}^{+}+\mathrm{O}^{+} \mathrm{e}^{-}$ & 22.37 \\
13 & $\mathrm{CO} \rightarrow \mathrm{O}^{+}+\mathrm{e}^{-}$ & 24.71 \\
14 & $\mathrm{O} \rightarrow \mathrm{O}^{+}+\mathrm{e}^{-}$ & 13.61 \\
15 & $\mathrm{O} \rightarrow \mathrm{O}^{++}+2 \mathrm{e}^{-}$ & 48.74 \\
16 & $\mathrm{O}^{+} \rightarrow \mathrm{O}^{++}+\mathrm{e}^{-}$ & 35.13 \\
\hline
\end{tabular}

Table 2. Sources for double-ionisation cross sections, either from theoretical estimates or from laboratory measurements.

\begin{tabular}{lc}
\hline \hline Ionisation & Photoionisation \\
\hline $\mathrm{N}_{2} \rightarrow \mathrm{N}_{2}{ }^{++}+2 \mathrm{e}^{-}$ & $\begin{array}{c}\text { Simon et al. (2005) theoretical estimates } \\
\text { This work, based on Samson (1990) }\end{array}$ \\
\hline $\mathrm{O} \rightarrow \mathrm{O}^{++}+2 \mathrm{e}^{-}$ & $\begin{array}{c}\text { Fennelly \& Torr (1992) } \\
\text { Angel \& Samson (1988) }\end{array}$ \\
\hline $\mathrm{CO}_{2} \rightarrow \mathrm{CO}_{2}^{++}+2 \mathrm{e}^{-}$ & Masuoka (1994) \\
\hline $\mathrm{O}^{+} \rightarrow \mathrm{O}^{++}+\mathrm{e}^{-}$ & Baluja \& Zeippen (1988) \\
& Kjeldsen et al. (2002) \\
Aguilar et al. (2003)
\end{tabular}

\section{The case of $\mathrm{O}^{++}$ions: comparison between modelled and measured densities}

The Pioneer Venus Orbiter carried 17 experiments, including a neutral mass spectrometer and an ion-mass spectrometer (Russell 1992). It allowed Hedin et al. (1983) to build a model of the Venusian thermosphere. However, although the mission lasted 14 years, no low-altitude data were being recorded during low solar activity, which put some constraints and uncertainties on the thermospheric model. The Ion and Neutral Mass Spectrometer (INMS) allowed the detection of atomic doublycharged ions such as $\mathrm{O}^{++}$(Taylor et al. 1980). However, the spectrometer was designed to detect only specific, preselected ions excluding $\mathrm{CO}_{2}^{++}$. The sensitivity threshold of INMS was 5 particles per $\mathrm{cm}^{3}$. The $\mathrm{N}_{2}{ }^{++}$dication cannot be distinguished from $\mathrm{N}^{+}$because both ions have the same $\frac{m}{q}$ ratio (where $m$ is the mass

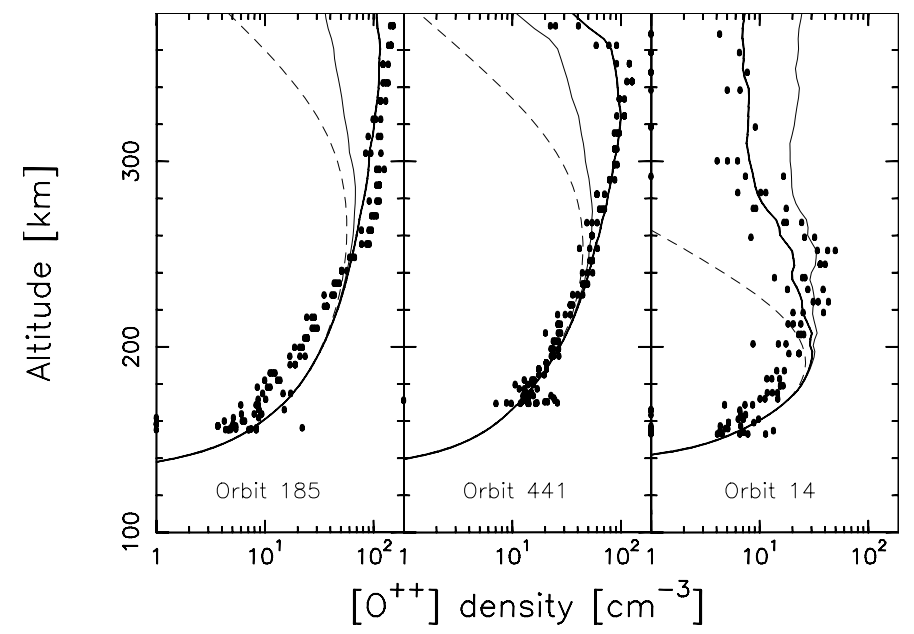

Fig. 1. The $\mathrm{O}^{++}$density comparison between the model and the PVO experiment. The black points correspond to the PVO measurements. The thick full lines shows the result of our modelling. The thin full lines correspond to the larger divergence when varying $\mathrm{H}$ between $5 \times 10^{4}$ and $2 \times 10^{5} \mathrm{~cm}^{-3}$ beyond $200 \mathrm{~km}$. The dashed lines correspond to the model without $\mathrm{O}^{+}$photoionisation.

and $q$ the charge). We have selected three orbits in the PVO data base, which represent three different geophysical conditions:

- Orbit 185: 1979-6-07; $F_{10.7} \approx 230$. Solar zenith angle $\approx 0^{\circ}$ : the usual orbit used for $\mathrm{O}^{++}$density calculations (Fox \& Victor 1981). The mean latitude over the orbit $\approx 0^{\circ}$.

- Orbit 441: $1980-2-19 ; F_{10.7} \approx 180$. Solar zenith angle $\approx 51^{\circ}$ : it is an orbit with a medium solar angle. The mean latitude over the orbit $\approx 0^{\circ}$.

- Orbit 14: $1978-12-18 ; F_{10.7} \approx 130$. Solar zenith angle $\approx 85^{\circ}$ : it is a boundary condition for both model and experimental conditions. The mean latitude over the orbit $\approx 15^{\circ}$.

The PVO measurements used as inputs in our model are the electron density, the electron temperature, and the $\mathrm{O}^{+}$density. The latter will be of utmost importance in the modelling, as the final density results are very sensitive to this parameter. As stated above, the solar flux comes from the EUV model of Tobiska (1993) and they correspond to the decimetric indexes on the day of the experiment. The ion temperature is adapted from Fox \& Sung (2001). The $\mathrm{H}$ densities have been inferred from Hartle et al. (1996). For orbit 185 and 441, their values are $5 \times 10^{4} \mathrm{~cm}^{-3}$ above $200 \mathrm{~km}$, corresponding to high solar activity. For orbit 14, the value is $2 \times 10^{5} \mathrm{~cm}^{-3}$ corresponding to a mean solar activity above the terminator.

The results are shown in Fig. 1. For orbit 185, the $\mathrm{O}^{++}$density was modelled by Fox \& Victor (1981). Using a photoionisation model, Fox computed a reaction rate constant of $k_{\mathrm{o}}=1.5 \pm$ $0.75 \times 10^{-9} \mathrm{~cm}^{3} \mathrm{~s}^{-1}$ for the reaction $\mathrm{O}+\mathrm{O}^{++} \rightarrow 2 \mathrm{O}^{+}$. This model took neither the electron impact ionisation nor the electron recombination of $\mathrm{O}^{++}$into account. More recently, the Simon et al. (2005) calculations on Earth showed a better agreement considering a constant rate of $k_{\mathrm{o}}=1.06 \pm 0.4 \times 10^{-9} \mathrm{~cm}^{3} \mathrm{~s}^{-1}$. We considered both values here, and found much better agreement with the second one. We did not need to adjust the other input parameters, like the input solar flux, the chemical reaction rates, the absorption and collision cross sections, and the neutral atmosphere.

The agreement is already very good in orbits 185 and 441 when the $\mathrm{O}^{+}$density used in the model comes from PVO measurements with $\mathrm{H}=5 \times 10^{4} \mathrm{~cm}^{-3}$ above $200 \mathrm{~km}$. This $\mathrm{H}$ density 


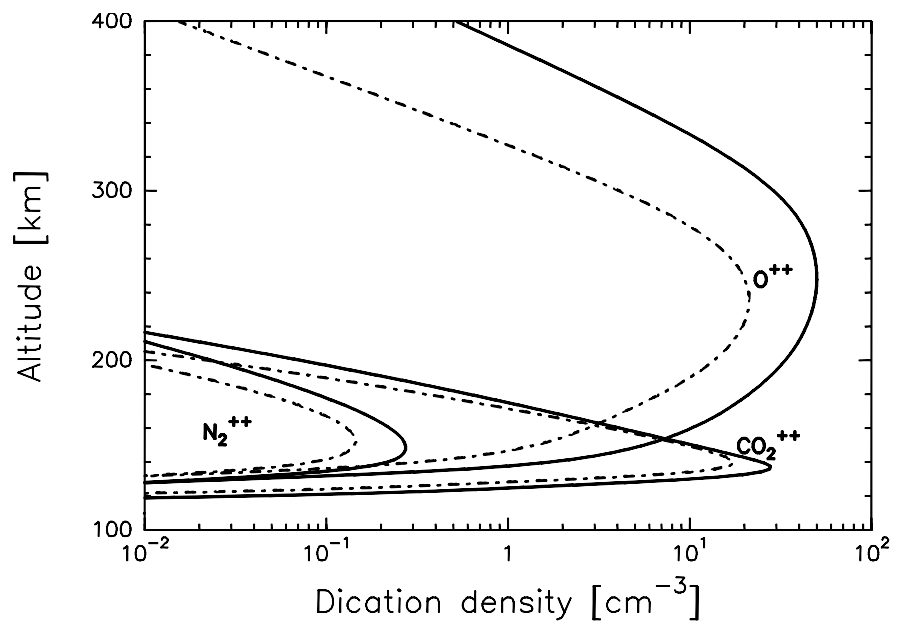

Fig. 2. $\mathrm{O}^{++}, \mathrm{N}_{2}{ }^{++}, \mathrm{CO}_{2}{ }^{++}$densities. Latitude: $45^{\circ}$, solar zenith angle: 45 $\mathrm{H}$ density: $5 \times 10^{4}$ Full lines: $F_{10.7}=200$. Dashed lines: $F_{10.7}=80$.

value is compatible with the solar conditions during orbit 185 as seen from Hartle et al. (1996). When this value is enhanced to $2 \times 10^{5} \mathrm{~cm}^{-3}$, the model and measurements diverge above $260 \mathrm{~km}$. When neglecting the single ionisation of $\mathrm{O}^{+}$(Fig. 1) a worse divergence occurs above the same altitude.

At low altitudes, the model slightly overestimates the $\mathrm{O}^{++}$density. According to Fox \& Sung (2001), the atomic O mixing ratio can be too high at high solar activity in the VTS3 model (Hedin et al. 1983), explaining this small discrepancy.

The 14 th orbit constitutes a boundary condition. The latitude is about $15^{\circ}$, while the solar zenith angle is $85^{\circ}$. In that case, we are at the planet's terminator. Moreover, the solar activity is lower $\left(F_{10.7} \approx 130\right)$. In these conditions, the $\mathrm{H}$ density is likely to be $2 \times 10^{5} \mathrm{~cm}^{-3}$ (Hartle et al. 1996). With this value, our model fits the measurements perfectly, while a lower $\mathrm{H}$ density value $\left(5 \times 10^{4} \mathrm{~cm}^{-3}\right)$ results in a degradation above $200 \mathrm{~km}$.

From these three cases, we have highlighted the usability range in which our model is valid.

\section{Dication densities}

In Fig. 2, we show the dication densities at a middle latitude in two solar conditions: strong $\left(F_{10.7}=200\right)$ and quiet $\left(F_{10.7}=80\right)$. We predict a $\mathrm{CO}_{2}{ }^{++}$layer centred on an altitude of $140 \mathrm{~km}$ with a density reaching $30 \mathrm{~cm}^{-3}$ in active solar conditions and $20 \mathrm{~cm}^{-3}$ in quiet solar conditions. These values are close to the $\mathrm{N}_{2}{ }^{+}$values (Fox \& Sung 2001). At a low altitude $(120 \mathrm{~km})$, they are higher than the $\mathrm{N}^{+}$or $\mathrm{C}^{+}$densities. The density of the $\mathrm{N}_{2}{ }^{++}$layer centred on $140-150 \mathrm{~km}$ altitude can reach $0.3 \mathrm{~cm}^{-3}$. This makes $\mathrm{N}_{2}{ }^{++}$a very minor ion in the Venusian ionosphere.

\section{Detectability of doubly-charged lons}

\section{1. $\mathrm{N}_{2}^{++}$}

The ion mass spectrometry technique cannot be used to detect $\mathrm{N}_{2}{ }^{++}$because this method performs the selection by the massto-charge $(\mathrm{m} / \mathrm{q})$ ratio. Lilensten et al. (2005) have shown that $\mathrm{N}_{2}{ }^{++}$may still be detected by fluorescence in the case of Titan. The emissive excited state $\mathrm{D}^{1} \Sigma_{u}^{+}$is $7.8 \mathrm{eV}$ above the ground state (Ahmad 2002; Olsson et al. 1988). Two bands corresponding to the $\mathrm{D}^{1} \Sigma_{u}^{+}-\mathrm{X}^{1} \Sigma_{g}^{+}(0,0)$ and $(1,1)$ transitions have already been observed experimentally in the 158.7-159.4 nm range (Cossart \& Launay 1985; Olsson et al. 1988). Using the results of Ehresmann et al. (2003), a rough approximation leads us to suppose that nearly $10 \%$ of the total of $\mathrm{N}_{2}{ }^{++}$ions created by double photoionisation at the cross-section peak near $65 \mathrm{eV}$ are produced in the $\mathrm{D}^{1} \Sigma_{u}^{+}$state. From a simple altitude integration, we would expect about 0.6 Rayleigh produced in the fluorescence state in quiet conditions and 1.7 Rayleigh in active solar conditions. These values are three times higher than those predicted on Titan.

The Venus Express SPICAV ultraviolet spectrometer has a range of $118-320 \mathrm{~nm}$ with a resolution of $1.5 \mathrm{~nm}$; therefore, the detection of such a fluorescence may be difficult but not impossible.

\section{2. $\mathrm{CO}_{2}^{++}$}

The $\mathrm{CO}_{2}{ }^{++}$dication has no significant known fluorescence line. Therefore, the most appropriate method of detection is the ionmass spectrometry technique. For $\mathrm{CO}_{2}{ }^{++}$the mass-to-charge ratio equals 22. Therefore this ion is a very good candidate for detection, since no other species in the Cytherean atmosphere has the same ratio. The closest ratios are 16 for $\mathrm{O}^{+}$and 28 for both $\mathrm{N}_{2}^{+}$and $\mathrm{CO}^{+}$. The only species with the same mass-tocharge ratio is the ${ }^{22} \mathrm{Ne}^{+}$ion. However the main isotope of $\mathrm{Ne}^{+}$ has an $m / q$ ratio of 20 , and its density in the Cytherean ionosphere is known to be extremely low, well below the density of $\mathrm{CO}_{2}{ }^{++}$predicted here. Thus no contamination from this component is likely to occur. Finally, the Analyser of Space Plasma and Energetic Atoms (ASPERA-4) onboard Venus Express was not designed to detect $\mathrm{CO}_{2}{ }^{++}$.

\section{Conclusions}

For the first time, the density of molecular dications has been modelled in the diurnal upper atmosphere of Venus. The $\mathrm{O}^{++}$ density was also computed and successfully compared to PVO measurements. These densities have been calculated by using a kinetic code for the production rates and a simple chemical scheme for the chemical losses. Doubly-charged ions were produced on the dayside through primary photoionisation and secondary electron impact ionisation. In the subsolar case, an additional source of ionisation may be solar-wind electrons and protons precipitating in the ionosphere and colliding with the thermosphere. These ions are essentially lost by dissociative recombination with thermal electrons and by chemical reactions with the neutral atmosphere. Consequently, a molecular dication layer can be created. The $\mathrm{CO}_{2}{ }^{++}$dication layer is centred on an altitude of $140 \mathrm{~km}$ with a density reaching $30 \mathrm{~cm}^{-3}$ in active solar conditions. The density of the $\mathrm{N}_{2}{ }^{++}$layer centred at $140-150 \mathrm{~km}$ altitude can reach $0.3 \mathrm{~cm}^{-3}$. The $\mathrm{O}^{++}$dication is most abundant at about $300 \mathrm{~km}$, with typical values of $80 \mathrm{~cm}^{-3}$. In the near future, we plan to extend our approach to electron precipitation from the solar-wind, a process which can play a major role in the upper atmosphere, depending on the solar activity. The measurement of molecular doubly-charged ions is a challenge for Venus Express and any planetary orbiter. The detection of such ions is of prime interest for the community involved in aeronomy studies that seek to understand their role in planetary ionospheres.

Acknowledgements. The authors wish to thank Mathieu Barthélemy (LPG, France) for helpful discussions and Héloise Soldi-Lose (Institut fur Chemie, Berlin, Germany) for useful advices. 


\section{References}

Aguilar, A., Covington, A. M., Hinojosa, G., et al. 2003, ApJS, 146, 467 Ahmad, M. 2002, Ph.D. Thesis, Université Paris VI,

Aitken, K. L., \& Harrison, M. F. A. 1971, J. Phys. B: At. Mol. Opt. Phys., 4, 1176

Angel, G., \& Samson, J. 1988, J. Phys. B: At. Mol. Opt. Phys., 21, 2441

Baluja, K., \& Zeippen, C. 1988, J. Phys. B: At. Mol. Opt. Phys., 21, 2441

Barabash, S., et al. 2006, Planet. Space Sci., in press

Bertaux, J.-L., et al. 2006, Planet. Space Sci., in press

Cossart, D., \& Launay, F. 1985, J. Mol. Spectr., 113, 159

Dutuit, O., Alcaraz, C., Gerlichc, D., et al. 1996, Chem. Phys., 209, 177

Ehresmann, A., Liebel, H., Schmoranzer, H., et al. 2003, J. Phys. B: At. Mol. Opt. Phys., 36, 3669

Fennelly, J. A., \& Torr, D. G. 1992, At. Dat. Nucl. Dat. Tab., 51, 321

Fox, J. L., \& Sung, K. Y. 2001, J. Geophys. Res., 106, 21305

Fox, J. L., \& Victor, G. A. 1981, J. Geophys. Res., 86, 2438

Franceschi, P., Thissen, R., Zabka, J., et al. 2003, Int. J. Mass Spectrom., 228, 507

Halas, S., \& Adamczyk, B. 1972, Int. J. Mass Spectrom. Ion Phys, 10, 157

Hartle, R. E., Donahue, T. M., Grebowsky, J. M., \& Mayr, H. G. 1996, J. Geophys. Res., 101, 4525

Häusler, B., Pätzold, M., Tyler, G. L., et al. 2006, Planet. Space Sci., 54, 1315

Hedin, A. E., Niemann, H. B., Kasprzak, W. T., \& Seiff, A. 1983, J. Geophys. Res., 88, 73

Hinteregger, H. E., Bedo, D. E., \& Manson, J. E. 1973, Rad. Sci., 8, 349

Honvault, P., Gargaud, M., Bacchus-Montabonel, M. C., \& McCarroll, R. 1995, A\&A, 302, 931

Itikawa, Y., \& Ichimura, A. 1990, J. Phys. Chem. Ref. Dat., 19, 637

Johnsen, R., \& Biondi, M. A. 1978, Geophys. Res. Lett., 5, 847

Kimura, M., Gu, J. P., Hirsch, G., \& Buenker, R. J. 1996, Phys. Rev. A, 53, 4164

Kjeldsen, H., Kristensen, B., Brooks, R. L., et al. 2002, ApJS, 138, 219

Krishnakumar, E., \& Srivastava, S. K. 1990, J. Phys. B: At. Mol. Opt. Phys., 23, 1893
Lilensten, J., \& Blelly, P. L. 2002, J. Atm. Terr. Phys., 64, 775

Lilensten, J., Witasse, O., Simon, C., et al. 2005, Geophys. Res. Lett., 32, 3203

Märk, T. D. 1975, J. Chem. Phys., 63, 885

Masuoka, T. 1994, Phys. Rev. A, 50, 3886

Mathur, D. 2004, Phys. Rep., 391, 1

Mathur, D., Andersen, L., Hvelplund, P., Kella, D., \& Safvan, C. 1995, J. Phys. B: At. Mol. Opt. Phys., 28, 3415

Nakada, M., \& Singer, S. 1968, Geophys. J. Roy. Astr. Soc., 15, 163

Olsson, B. J., Kindvall, G., \& Larsson, M. 1988, J. Chem. Phys., 88, 7501

Richards, P. G., Fennelly, J. A., \& Torr, D. G. 1994, J. Geophys. Res., 99, 13283

Russell, C. T. 1992, Washington DC American Geophysical Union Geophysical

Monograph Series, 66, 225

Samson, J. A. 1990, Phys. Rev. Lett., 65, 2861

Seiersen, K., Al-Khalili, A., Heber, O., et al. 2003a, Phys. Rev. A, 68, 022708

Seiersen, K., Heber, O., Jensen, M. J., Safvan, C. P., \& Andersen, L. H. 2003b, J. Chem. Phys., 119, 839

Simon, C., Lilensten, J., Dutuit, O., et al. 2005, Ann. Geoph., 23, 781

Straub, H. C., Renault, P., Lindsay, B. G., Smith, K. A., \& Stebbings, R. F. 1996, Phys. Rev. A, 54, 2146

Taylor, H. A., Brinton, H. C., Bauer, S. J., et al. 1980, J. Geophys. Res., 85, 7765

Tian, C., \& Vidal, C. R. 1998, J. Chem. Phys., 108, 927

Tobiska, W. K. 1991, J. Atm. Terr. Phys., 53, 1005

Tobiska, W. K. 1993, J. Geophys. Res., 98, 18879

Tobiska, W. K., \& Eparvier, F. G. 1998, Sol. Phys., 177, 147

Torr, D. G., \& Torr, M. R. 1979, J. Atm. Terr. Phys., 41, 797

Torr, M. R., \& Torr, D. G. 1985, J. Geophys. Res., 90, 6675

Witasse, O., Dutuit, O., Lilensten, J., et al. 2002, Geophys. Res. Lett., 29, 104

Witasse, O., Dutuit, O., Lilensten, J., et al. 2003, Geophys. Res. Lett., 30, 12

Witasse, O., \& Nagy, A. F. 2006, Planet. Space Sci., 54, 1381

Yamada, I., Danjo, A., Hirayama, T., et al. 1988, J. Phys. Soc. Jpn., 57(8), 26992704

Ziegler, D. L., Newman, J. H., Smith, K. A., \& Stebbings, R. F. 1982, Planet. Space Sci., 30, 451

Zipf, E. C. 1985, Planet. Space Sci., 33, 1303 